ERRATUM

\title{
Denosumab for bone diseases: translating bone biology into targeted therapy
}

\author{
Elena Tsourdi ${ }^{1, *}$, Tilman D Rachner ${ }^{1, *}$, Martina Rauner ${ }^{1}$, Christine Hamann ${ }^{2}$ and Lorenz C Hofbauer ${ }^{1,3}$
}

${ }^{1}$ Division of Endocrinology, Diabetes, and Bone Diseases, Department of Medicine III, Technical University Medical Center, Fetscherstrasse 74, D-01307 Dresden, Germany, ${ }^{2}$ Department of Orthopedics, Technical University Medical Center, D-01307 Dresden, Germany and ${ }^{3}$ Center for Regenerative Therapies Dresden, D-01307 Dresden, Germany

(Correspondence should be addressed to L C Hofbauer at Division of Endocrinology, Diabetes, and Bone Diseases, Department of Medicine III, Technical University Medical Center; Email: lorenz.hofbauer@uniklinikum-dresden.de)

*(E Tsourdi and T D Rachner contributed equally to this work)

The authors and the journal apologise for an error in this article published in the European Journal of Endocrinology 2011 Vol 165 pp 833-840. In table 2, the direction of the first arrow in the column titled Fx/SRE should be pointing downwards and not as published. The correct table is published in full below.

European Journal of Endocrinology 166137

Table 2 Denosumab studies.

\begin{tabular}{|c|c|c|c|c|c|c|}
\hline \multirow[b]{2}{*}{ Name } & \multirow[b]{2}{*}{ Phase } & \multirow[b]{2}{*}{$n$} & \multicolumn{3}{|c|}{ Results } & \multirow[b]{2}{*}{ References } \\
\hline & & & BTM & BMD & Fx/SRE & \\
\hline Single-dose placebo-controlled in postmenopausal women & 1 & 49 & $\downarrow$ & NA & NA & (24) \\
\hline Efficacy and safety in postmenopausal women with low BMD & 2 & 412 & $\downarrow$ & $\uparrow$ & NA & (33) \\
\hline Treatment of postmenopausal osteoporosis (FREEDOM) & 3 & 7868 & $\downarrow$ & $\uparrow$ & $\downarrow$ & (37) \\
\hline Prevention of postmenopausal osteoporosis & 3 & 332 & $\downarrow$ & $\uparrow$ & NA & (35) \\
\hline $\begin{array}{l}\text { Comparison with alendronate in postmenopausal women with } \\
\text { low BMD (DECIDE) }\end{array}$ & 3 & 1189 & $\downarrow$ & $\uparrow$ & NA & (39) \\
\hline $\begin{array}{l}\text { Treatment of bone loss in men on androgen deprivation } \\
\text { treatment for non-metastatic prostate cancer (HALT) }\end{array}$ & 3 & 1468 & NA & $\uparrow$ & $\downarrow$ & (41) \\
\hline $\begin{array}{l}\text { Treatment of bone loss in women on aromatase inhibitors for } \\
\text { non-metastatic breast cancer }\end{array}$ & 3 & 252 & NA & $\uparrow$ & NA & (40) \\
\hline $\begin{array}{l}\text { Denosumab versus zoledronic acid for the treatment of bone } \\
\text { metastases in advanced breast cancer }\end{array}$ & 3 & 2046 & $\downarrow$ & NA & $\downarrow$ & (42) \\
\hline $\begin{array}{l}\text { Denosumab versus zoledronic acid for the treatment of bone } \\
\text { metastases in castration-resistant prostate cancer }\end{array}$ & 3 & 1904 & $\downarrow$ & NA & $\downarrow$ & (43) \\
\hline
\end{tabular}

BMD, bone mineral density; BTM, bone turnover marker; Fx, fracture; NA, not available; SRE, skeletal-related event. 